\title{
Presence of Inguinal Hernia in Soccer Players with Osteitis Pubis
}

\section{Osteitis Pubisli Futbolcularda İnguinal Herni Varlı̆̆̊*}

\author{
Ali Eraslan ${ }^{1}$, Ayşen Türk ${ }^{1}$, Bekir Erol ${ }^{2}$ \\ ${ }^{1}$ University of Health Sciences, Antalya Education and Research Hospital, Department of Sports Medicine, Antalya, Turkey \\ 2 University of Health Sciences, Antalya Education and Research Hospital, Department of Radiology, Antalya, Turkey
}

\section{A. Erarslan (iD) \\ 0000-0001-6909-8198 \\ A. Türk (D) \\ 0000-0002-1978-0401 \\ B. Erol (iD \\ 0000-0002-9444-3405}

Geliş Tarihi / Date Received: 04.08.2017

Kabul Tarihi / Date Accepted: 26.09.2017

Yayın Tarihi / Date Published: 29.11.2017

Yazışma Adresi /

Corresponding Author:

Ali Eraslan

Sağlık Bilimleri Üniversitesi, Antalya Eğitim ve Araştırma Hastanesi, Spor Hekimliği Birimi, Antalya, Turkey.

E-mail: eraslanali@yahoo.com

๑๐2017 Türkiye Spor Hekimleri Derneği. Tüm hakları saklıdır.

\begin{abstract}
Objective: Groin pain is one of the most important health problems in soccer. Its causes include musculo-tendinous injuries, osteitis pubis, inguinal hernia, sports hernia, avulsion fractures, hip pathologies and urogenital problems. In this study, it was aimed to investigate the presence of inguinal hernia in soccer players with osteitis pubis.

Material and Methods: Archive records of male soccer players who were admitted to the sports medicine clinic with groin pain, and diagnosed with osteitis pubis were screened retrospectively. Pelvic MR images and inguinal USG results were reviewed.

Results: A total of 51 soccer players with osteitis pubis were detected in the archive records. There were eight osteitis pubis cases (15.6\%) associated with inguinal hernia. Three athletes $(5.8 \%)$ had undergone hernia operation before admission. The remaining five $(9.8 \%)$ were concomitant cases of inguinal hernia and osteitis pubis. In seven of the eight cases, ipsilateral findings of osteitis pubis were more severe than those with contralateral hernia.

Conclusion: The study revealed that soccer players with osteitis pubis may have concomitant inguinal hernia, and that osteitis pubis may develop in soccer players who have undergone hernia repair. In addition, more severe osteitis pubis findings on the same side with hernia indicate that the two pathologies occur with common mechanisms. It should not be forgotten that inguinal hernia be considered in the differential diagnosis of osteitis pubis, which it may accompany. Conservative methods are mostly used in the treatment of osteitis pubis, whereas the treatment of inguinal hernia is surgery. If only one entity is diagnosed when both are present, the success of treatment will decrease.
\end{abstract}

Key Words: Inguinal hernia, osteitis pubis, soccer

\section{ÖZ}

Amaç: Kasık ağrısı futbolda en önemli sağlık sorunlarından biridir. Nedenleri arasında sıklıkla kas-tendon zorlanmaları, osteitis pubis, inguinal herni, sporcu hernisi, avülsiyon kırıkları, kalça eklemi patolojileri ve ürogenital problemler yer alır. Bu çalıșmada osteitis pubis tanısı konulmuş futbolcularda inguinal herni varlığını araştırmak amaçlandı.

Gereç ve Yöntemler: Spor hekimliği polikliniğine kasık ağrısıyla başvurmuş ve osteitis pubis tanısı konulmuş erkek futbolcuların arşiv kayıtları retrospektif olarak tarandı. Pelvik Manyetik Rezonans (MR) görüntüleri ve inguinal Ultrasonografi (USG) sonuçları incelendi.

Bulgular: Arşiv kayıtlarından 51 osteitis pubisli futbolcunun MR görüntülerine ulaşıldı. İnguinal herni ile birlikte görülen sekiz (\%15.6) osteitis pubis olgusu bulundu. Üç sporcu (\%5.8) polikliniğe başvurmadan önce herni operasyonu geçirmişti. Geriye kalan beş sporcuda (\%9.8) ise osteitis pubis ile eş zamanlı inguinal herni saptanmıştı. Sekiz olgunun yedisinde herniyle ipsilateral osteitis pubis vardı ve bir olgudaki kontralateral osteitis pubise kıyasla bulgular daha şiddetliydi.

Sonuç: Çalışmanın sonuçları osteitis pubisli futbolcularda eş zamanlı inguinal herni olabileceğini ve herni onarımı geçirmiş futbolcularda osteitis pubis gelişebildiğini göstermiştir. Bunun yanı sıra, herni ile aynı taraftaki osteitis pubis bulgularının daha şiddetli oluşu iki patolojinin ortak mekanizmalarla geliştiğine işaret etmektedir. İnguinal herninin osteitis pubisin ayırıcı tanısında değerlendirilmesi ve ona eşlik edebileceği 
unutulmamalıdır. Osteitis pubisin tedavisinde çoğunlukla konservatif yöntemler uygulanırken, inguinal herninin tedavisi cerrahidir. İki patoloji birlikte iken sadece birine tanı konulması durumunda tedavinin başarı şansının azalabileceği göz önünde bulundurulmalıdır.

Anahtar Sözcükler: İnguinal herni, osteitis pubis, futbol

Available at: http://journalofsportsmedicine.org and http://dx.doi.org/10.5152/tjsm.2017.080

Cite this article as: Eraslan A, Türk A, Erol B. Presence of inguinal hernia in soccer players with osteitis pubis. Turk $J$ Sports Med. 2017;52:133-6.

*Bu çalışma, 2-5.04.2017 tarihinde Antalya'da düzenlenen 16. Ulusal Spor Hekimliği Kongresinde poster bildiri olarak sunulmuştur.

\section{GíRIŞ}

Kasık bölgesi karmaşık anatomik yapıya sahip ve sportif aktivite sırasında tekrarlayıcı mekanik strese uğrayan bir bölgedir. Futbol, hokey, ragbi ve Amerikan futbolu gibi bazı spor branşlarında bu mekanik stresin dozu daha yüksektir (1). Sporcularda gözlenen bașlıca kasık problemleri arasında kas-tendon problemleri (adduktor, rektus abdominis, rektus femoris, iliopsoas kasları), avülsiyon kırıkları, stres kırıkları, osteitis pubis, alt karın duvarı yetmezlikleri (inguinal herni ve herni kesesinin saptanamadığı sporcu hernisi), kalça eklemi patolojileri (femoro-asetabular "impingement", labral yırtık, bursit), tuzak nöropatiler ve ürogenital problemler (enfeksiyon, ürolitiyazis, varikosel, inguinal lenfadenopati) bulunmaktadır (1-3).

Osteitis pubis, sporcularda simfizis pubisin ve çevresindeki yapıların ağrılı, enflamatuar ve non-enfeksiyöz bir patolojisidir (4). Etyolojisinde kronik zorlayıcı mikro-travmalar, akut yüksek enerjili travmalar, abdominal ve adduktor kaslar arasındaki imbalans, simfizis pubisde anormal vertikal hareket, kalça ekleminin rotasyonel hareket açıklığında azalma ve sakroiliak disfonksiyon yer alır $(3,4)$. Yüksek yoğunlukta egzersizler, ani hızlanma ve yavaşlama, şut çekme, keskin yön değiştirme ve pivot hareketleri pubik bölgede traksiyon ve makaslama kuvvetlerine yol açarak osteitis pubis gelişimini kolaylaştırırlar. Simfizis pubis ve pubik kemiklerde ödem, enflamasyon ve zamanla gelișen dejeneratif değişiklikler patolojik bulgulardır $(3,5)$.

Sporcularda kronik kasık ağrısı tek bir patolojiye bağlı olabileceği gibi, birden fazla patolojinin eş zamanlı varlığına da bağlı olabilir $(6,7)$. Konuya ilişkin literatür verileri kısıtlıdır. Bu çalışmada, kasık ağrısı nedenlerinden biri olan inguinal herninin osteitis pubis tanısı konulmuş futbolcularda varlığını araştırmak amaçlandı.

\section{GEREÇ ve YÖNTEMLER}

Retrospektif olarak tasarlanan çalışma için öncelikle Hastane Etik Kurulundan onay alındı. Spor hekimliği polikliniğine 2011-2016 yılları arasında kasık ağrısıyla başvuran sporcuları saptamak amaciyla hastanenin "online bilgi yönetim sistemi" kayıtları ve manüel olarak tutulan poliklinik kayıtları incelendi. Klinik bulgular ve manyetik rezonans görüntüleme (MRG) bulgularının uyumuyla osteitis pubis tanısı konulmuş olan sporcular bulundu.

Sporcuların demografik özellikleri (yaş, cinsiyet, spor branşı), pelvik MR görüntüleri ve inguinal ultrasonografi (USG) sonuçları incelendi. Kadın cinsiyet ve futbol dışındaki spor branşları çalışmaya dahil edilmedi. MRG veya USG tetkikleri dış merkezde yapılmış olan futbolcular telefonla aranarak tetkik materyallerine ulaşılmaya çalışıldı. İstatistiksel analizde devamlı değişkenler ortalama ve standart sapma olarak, kategorik değişkenler yüzdelik oran olarak belirtildi.

\section{BULGULAR}

Retrospektif tarama sonucunda osteitis pubisli 51 futbolcunun kayıtlarına ulaşıldı. Sporcuların 34'ü lisanslı (amatör veya profesyonel liglerde), 17'si rekreasyonel olarak futbol oynamaktaydı. Yaş ortalaması $24.5 \pm 7.7 \mathrm{yll}$ bulundu. Adduktor kasında veya tendonunda artmış sinyal değişiklikleri, MR görüntülerinde osteitis pubise eşlik eden en sık ikinci patolojiydi. Değişik 
derecelerde kas zorlanması veya tendon yapışma yerinde mikroyırtık olarak tanımlanan bu lezyonlar 32 hastada (\%62) bulunmaktaydı.

İnguinal herniyle ilişkili sekiz (\%15.6) osteitis pubis olgusu bulundu. Üç sporcu (\%5.8) polikliniğe başvurmadan önce inguinal herni operasyonu geçirmişti (ikisi sağ, biri sol). Toplam 26 sporcuya kasık ağrısıla birlikte herni semptomları da (Valsalva manevrası ile inguinal ağrının artışı) tanımladıkları için herni muayenesi ve dinamik inguinal USG uygulanmıştı. Klinik ve radyolojik bulguların birlikteliğiyle bu sporcuların beșinde (\%9.8) inguinal herni saptanarak cerrahiye sevk edilmişti (üçünde sol, ikisinde sağ).

İnguinal herni bulunan sekiz olgunun hepsinin MR görüntüsünde bilateral osteitis pubis vardı. Bunların yedisinde (\%87.5) herniyle ipsilateral osteitis pubis bulguları kontralateral osteitis pubisten daha şiddetliydi. Yalnızca bir olguda osteitis pubis bulguları sağ ve sol pubik ramusta aynı şiddetteydi.

\section{TARTIŞMA}

Kasık sorunları, popüler ve finansal açıdan önemli bir spor olan futbolda sporcuların performansını düşürerek ciddi zaman ve kazanç kayıplarına neden olmaktadır. Osteitis pubis futbolcularda sık görülen bir kasık ağrısı nedenidir $(5,8)$. Așırı ve zorlayıcı atletik yüklenmenin simfizis pubis ve parasimfizeal kemiklerde meydana getirdiği stres reaksiyonuna bağlı olarak gelişir. Ağrı zamanla artış gösterebilir ve sporcunun aktivitesini yüksek düzeyde sürdürmesine izin vermez (3).

Literatürde osteitis pubis ile eş zamanlı olarak diğer kasık ağrısı nedenlerinin de bulunabileceği belirtilmiştir. Lovell 189 kronik kasık ağrılı sporcu üzerinde yaptığı çalışmada osteitis pubisli 26 olgu bildirmiş ve bu olguların \%46'sında ikinci bir kasık patolojisinin varlığına (çoğunlukla adduktor lezyonu) işaret etmiştir (7). Futbolcular üzerindeki araştırmalarda da, osteitis pubisli olguların sıklıkla adduktor tendon yaralanmasına sahip oldukları bildirilmiştir $(5,8)$. Benzer bir sonuç bu çalışmada da ortaya çıktı ve osteitis pubisli futbolcuların \%62'sinde adduktor lezyonları saptandı.

Çalışmada adduktor lezyonların yanı sıra, sporcularda bir diğer kasık ağrısı etkeni olan inguinal herninin (9-11) osteitis pubise eşlik edip etmediğini araştırmak amaçlandı. Çalışmanın sonuçları osteitis pubisli futbolcularda eş zamanlı inguinal herni olabileceğini ve önceden inguinal herni onarımı geçirmiş futbolcularda osteitis pubise rastlanabileceğini gösterdi. İki patolojiden hangisinin daha önce geliştiği hakkında kesin bir yorum yapmak güçtür. Ancak herninin (opere veya nonopere) olduğu taraftaki pubik ramusta osteitis pubis bulgularının daha şiddetli oluşu, iki patolojiye yol açan mekanizmaların ortak olabileceğine işaret etmektedir.

Literatüre bakıldığında sporcularda açık inguinal herniden çok sporcu hernisi ("sports hernia") olarak adlandırılan, herni kesesinin saptanamadığı ve tanı konulmasında güçlük çekilen klinik antite göze çarpmaktadır. "Athletic pubalgia", "Gilmore's groin”, "sportsman's groin”, "hockey player's syndrome", "occult hernia", "incipient hernia", "pubic inguinal pain syndrome" ve son olarak "inguinal disruption" adiyla da anılan sporcu hernisi inguinal herninin başlangıç aşaması olarak tanımlanmaktadır (12-15). İnguinal hernide olduğu gibi sporcu hernisi olgularının çoğunda öksürme, hapşırma ve Valsalva manevrasıyla kasık ağrısında artış gözlenmektedir $(12,14)$. Çalışmada yer alan 26 sporcu herni benzeri semptomlardan yakınmasına karşın bunların ancak beşinde klasik inguinal herni saptanmıștı. İnguinal herni bulunmayan bazı olgularda sporcu hernisi olması veya inguinal herni bulunan bazı olguların sporcu hernisi zemininde gelişmiş olmasından söz edilebilir.

Sonuç olarak; osteitis pubis ve inguinal herni hem birbirlerinin ayırıcı tanısında düşünülmeli, hem de birliktelik gösterebilecekleri konusu unutulmamalıdır. İki patoloji birlikte iken sadece birine tanı konulması durumunda tedavinin başarı şansı azalacaktır. Çünkü osteitis pubis sıklıkla konservatif yöntemlerle tedavi edilirken $(3,4)$, inguinal herni varlığında cerrahi girişim esastır 
$(9,11)$. Futbolcularda herni onarımı uygulansa bile, abdominal/adduktor kas zayıflığı ve imbalansı giderilmeden spora dönülmesi de sonradan osteitis pubis gelişimine zemin hazırlayabilir.

\section{KAYNAKLAR}

1. Falvey EC, Franklyn-Miller A, McCrory PR. The groin triangle: a patho-anatomical approach to the diagnosis of chronic groin pain in athletes. Br J Sports Med. 2009; 43(3): 213-20.

2. Macintyre J, Johson C, Schroeder EL. Groin pain in athletes. Curr Sports Med Rep. 2006;5(5):293-9.

3. Hiti CJ, Stevens KJ, Jamati MK, et al. Athletic Osteitis Pubis. Sports Med. 2011;41(5):361-76.

4. Mandelbaum B, Mora SA. Osteitis pubis. Oper Tech Sports Med. 2005;13:62-7.

5. Kunduracioglu B, Yilmaz C, Yorubulut M, et al. Magnetic resonance findings of osteitis pubis. J Magn Reson Imaging. 2007;25(3):535-9.

6. Ekberg O, Persson NH, Abrahamsson PA, et al. Longstanding groin pain in athletes. A multidisciplinary approach. Sports Med. 1988;6:56-61.

7. Lovell G. The diagnosis of chronic groin pain in athletes: a review of 189 cases. Aust J Sci Med Sport. 1995;27(3): 76-9.

8. Cunningham PM, Brennan D, O'Connell M, et al. Patterns of bone and soft-tissue injury at the symphysis pubis in soccer players: observations at MRI. AJR Am J Roentgenol. 2007;188(3):W291-6.

9. Taylor DC, Meyers WC, Moylan JA, et al. Abdominal musculature abnormalities as a cause of groin pain in athletes. Inguinal hernias and pubalgia. Am J Sports Med. 1991;19(3):239-42.

10. Rich BS, Hough DO, Monroe JS, et al. Inguinal mass in a college football player: a case study. Med Sci Sports Exerc. 1993;25(3):318-20.

11. Van Veen RN, de Baat P, Heijboer MP, et al. Successful endoscopic treatment of chronic groin pain in athletes. Surg Endosc. 2007;21(2):189-93.

12. Farber AJ, Wilckens JH. Sports hernia: diagnosis and therapeutic approach. J Am Acad Orthop Surg. 2007;15(8): 507-14.

13. Litwin DE, Sneider EB, McEnaney PM, et al. Athletic pubalgia (sports hernia). Clin Sports Med. 2011;30(2): 417-34.

14. Ekci B, Beyzadeoglu T. Groin pain in athletes - sports hernia and osteitis pubis. In: Canonico S (editors). Inguinal Hernia [online]. InTech; 2014, p. 111-23. doi: 10.5772/58621. Available from: https://intechopen.com/ books/inguinal-hernia/groin-pain-in-athletes-sportshernia-and-osteitis-pubis.

15. Sheen AJ, Stephenson BM, Lloyd DM, et al. 'Treatment of the sportsman's groin': British Hernia Society's 2014 position statement based on the Manchester Consensus Conference. Br J Sports Med. 2014;48(14):1079-87. 